Malaspina University-College, British Columbia

\author{
Keith Harrison
}

\title{
Narrative Theory / Creative Acts?
}

The narratives of the world are numberless. (Barthes 79)

In fact, theory doesn't silence the writer at all; it enlarges the boundaries. I meet a lot of writers in Canada who have blocked, and the problem is often, it seems to me, rooted in an insufficiency of theory. They have come to the end of what they've picked up unconsciously, and they don't know how to break through to a new plateau. And I swear it's theory that would help them out. (Kroetsch 24)

This is the paradox of every poetics, and doubtless of every other activity of knowledge as well: always torn between those two unavoidable commonplaces - that there are no objects except particular ones and no science except of the general - but always finding comfort and something like attraction in this other, slightly less widespread truth, that the general is at the heart of the particular, and therefore (contrary to the common perception) the knowable is at the heart of the mysterious. (Genette 23)

I'm really glad people are starting to think about theory because... entertaining any such thoughts used to be that somehow your vital juices would dry up... if you got involved in theory, that somehow it was zero sum game and that your creativity would suffer. Twenty pounds of the genius of writing would have to be removed in order to cram in twenty pounds of theory. That's crazy. (Bowering 24)

Though the theoretical study of narrative and the practice of creative writing are usually treated as distinct, even as oppositional, there are places of illuminating convergence, such as the stories and novels of John Barth. Yet on the part of writers a deep distrust of narrative theory persists, a romantic resistance to becoming conscious of fictional forms. This sometimes-justified suspicion of the thought-out as opposed to the felt, often with rooted beliefs in the Muse or the Unconscious or the Body, nourishes a mystique of the inspired artist. But this wish for spontaneous, untutored originality conflicts with the very etymology of "narrating", which means "knowing". 
For story-tellers, during certain phases of composition, an avoidance of selfconscious technique might offer needed emotional space, as well as possibilities of textual discovery; however, artistry in fiction means skillfully realizing informed expressive choices. The reader's sense that a superb novel feels magical derives from what is invisible: the writer's laboursome (and exciting) process of finding the linguistic rightness and the apt story-telling form to create that magic. I am convinced that, ultimately, novelists have to know about narrating. And within the profuse energies of thinking about literature in the last few decades, a place of much activity has been narrative theory.

Unfortunately, in seeking to clarify how stories are told, formed, transposed, and received, narrative theorists have also made a lot of smoke. Some of this smokiness results from vocabularies that are erudite, new-coined, exotic, heavyhanded, whimsical, and partly overlapping. But most of the obfuscating smoke in narrative theory comes from the dozens of different fires lit to illuminate different vantage points of a shared terrain. Examples of critical terms that are initially baffling but might prove useful for fiction writers are defamiliarization, closure, mise-en-abyme, double voicedness, dialogism, double focalization, and scripts. These theoretical terms can both spark an initiating sense of design possibilities and illuminate the mysterious acts of revision, where a writer often intuits that something is not working, but can't quite figure out why. It is the aim of the following writerly experiments with narrative theory to examine a few sites of brightness, and to suggest how such theoretical flares might be of value in the creating of fiction.

\section{Defamiliarization}

After we see an object several times, we begin to recognize it. The object is in front of us and we know about it, but we do not see it - hence we cannot say anything significant about it. Art removes objects from the automatism of perception in several ways. Here I want to illustrate a way used repeatedly by Leo Tolstoy, that writer who... seems to present things as if he himself saw them, saw them in their entirety, and did not alter them. Tolstoy makes the familiar seem strange by not naming the familiar object. He describes an object as if he were seeing it for the first time, an event as if it were happening for the first time. In describing something he avoids the accepted names of its parts and instead names corresponding parts of other objects. For example, in Shame Tolstoy 'defamiliarizes' the idea of flogging.... (Shklovsky 13)

According to this perspective on language and art, the "estranging" effects of literature are desirable because they disrupt the routinized perceptions of everyday life. Chris Baldick finds interesting parallelisms to this concept of defamiliarization in both Romantic poetry and in Brecht's theatre:

Samuel Taylor Coleridge... wrote of the 'film of familiarity' that blinds us to the wonders of the world, and that Wordsworth's poetry aimed to remove. P.B. Shelley... also claims that poetry 'makes familiar objects be as if they were not familiar' by stripping 'the veil of familiarity from the world'. ...Brecht's theory of the alienation effect in drama starts from similar grounds.

(Baldick 54) 
These correspondences point to an aesthetic of self-conscious artistry that is opposed to a simple "slice-of-life" realism that seeks merely to duplicate habits of language.

\section{Experiments:}

1. Narrate in two ways an incident of someone knocking over a drink during his or her first encounter with an attractive person: first, simply designate the other character as "handsome" or "beautiful"; second, omit such an abstraction and create through vivid description a startled sensation of physical attractiveness.

2. Write a description of a character's appearance which uses clichés, and then another description using unexpected and unusual words. Which passage works better and why? What can be lost in straining after unfamiliar language? What can sometimes be achieved?

3. As an exercise in setting, describe how the same room looks to someone who is five, then to someone else who is eighty. In both cases choose diction and syntax that are fresh.

4. To create a character who is suicidal, try sketching an interior monologue in sentence fragments.

5. A famous writing exercise invented by John Gardner is the following one: "Describe a building as seen by a man whose son has just been killed in a war. Do not mention the son, war, death, or the old man doing the seeing; then describe the same building, in the same weather and at the same time of day, as seen by a happy lover. Do not mention love or the loved one" (Gardner 203). Find vivid language to describe how a kitchen looks to someone who has just learned of the death of someone very close, and then, in another paragraph, describe how that same kitchen looks to someone who has just fallen in love. Is setting more subjective than objective?

6. Convey three distinct emotions by describing a character's perception of a key object in her or his life three times: first encounter, later in time, and a final glimpse. Don't identify the object.

\section{Closure}

We have our vital interest in the structure of time, in the concords books arrange between beginning, middle, and end. ...Our geometries, in James's word, are required to measure change, since it is on change, between remote or imaginary origins and ends, that our interests are fixed. In our perpetual crisis we have, at the proper seasons, under the pressure perhaps of our own end, dizzying perspectives upon the past and the future, in a freedom which is the freedom of a discordant reality. Such a vision of chaos or absurdity may be more than we can easily bear.... Merely to give order to these perspectives is to provide consolation, as De Quincey's opium did: and simple fictions are the opium of the people. But fictions too easy we call 'escapist': we want them not only to console but to make discoveries of the hard truth here and now in the middest [in the midst of life]. We do not feel they are doing this if we cannot... hear the discoveries of dissonance, the word set against the word. The books which seal off the long perspectives, which sever us from our losses, which represent the world of potency as a world of act, these are the books which, when the drug wears off, go on to the dump with the other empty bottles. Those that continue to interest us move through time to an 
end, an end we must sense even if we cannot know it... (Kermode 178-79)

In his commentary on the lack of concordance between a "comfortable story and the non-narrative contingencies of modern reality" (Kermode 128), Kermode speaks of some plots as being "too consolatory to console" (Kermode 164), and prefers the difficult sense of an ending articulated by Henry James who argues that "'relations stop nowhere, and the exquisite problem of the artist is eternally to draw, by a geometry of his own, the circle in which they shall happily appear to do so'" (quoted. in Kermode 176). This paradoxical closure, one which only seems complete, perhaps also relates to Bakhtin's notion that the novel as a form involving time defines itself by unfinalizability, a quality of "becoming" (Bakhtin 1981: passim). Much of modern fiction with its "successiveness of time" (Kermode 176) makes widespread use of an open ending that feels more like a pause than a finality, since even after the last page there remain gaps and questions and impulses to further narrative.

\section{Experiments:}

1. Take a story you have written and transpose the ending from upbeat to downbeat, or vice versa. Does it falsify the previous stretch of narrative, or does it reveal a hidden potentiality? Are there ironic effects? If the transposed ending works effectively, might it be a measure of the indeterminacy in the character's life?

2. End a story with a car or plane accident. Why do readers usually resent accidental endings in narrative when they can occur in real life?

3. "Since reality is incomplete, art must not be too afraid of incompleteness" (Iris Murdoch quoted. in Kermode 130). Take a story you have completed, and put a significant gap into the ending. Does this interest or frustrate your readers?

4. Read a story for the first time and stop before the final paragraph. Write your own last paragraph, then compare it with the author's. Try this experiment with the very last sentence. How closely does your version match the author's in action, image, and tone?

5. David Lodge suggests that "the short story is essentially 'end-oriented', inasmuch as one begins a short story in the expectation of soon reaching its conclusion, whereas one embarks upon a novel with no very precise idea of when one will finish it. We tend to read a short story in a single sitting, drawn along by the magnetic power of its anticipated conclusion; whereas we pick up and put down a novel at irregular intervals, and may be positively sorry to come to the end of it" (Lodge 225). Is there more openness at the end of your shorter or longer works of fiction?

6. Write a story that is resolutely set in the "now", with no hints of long perspectives, of birth or death. Does this limitation (by denying a sense of time and change, which imply beginning and ending) make narrative impossible?

7. Write a short story that has two endings: one in which all questions are answered ("'a distribution at the last of prizes, pensions, husbands, wives, babies, millions, appended paragraphs, and cheerful remarks"' [James quoted. in Kermode 22]), and a second version that leaves significant gaps. Which do you prefer? Which do you prefer to reread?

\section{Mise-en-abyme}

An analogy which verges on identity... is known in French as mise-en-abyme. It can be described as the equivalent in narrative 
fiction of something like Matisse's famous painting of a room in which a miniature version of the same painting hangs on one of the walls. Ever since Gide's expression of a predilection for miseen-abyme, described in his journals as a transposition of the theme of a work to the level of the characters, the technique has been much discussed. ...A famous example from Gide's own work is The Counterfeiters (1949) where a character is engaged in writing a novel similar to the novel in which he appears.

(Rimmon-Kenan 93)

This narrative holding up of the mirror to itself in the very act of mirroring the outside world creates a metafictional consciousness within the reader who is constantly aware of the fictive process. As Chris Baldick indicates, "[t]he 'Chinese box' effect of mise-en-abyme often suggests an infinite regress, i.e. an endless succession of internal duplications. It has become a favoured device in postmodernist fictions by Jorge Luis Borges, Italo Calvino, and others" (Baldick 138). Such works, through the use of mise-en-abyme, simultaneously create and reflect upon their themes, often reflexively blurring the traditionally separate planes of characterization and fictional form.

\section{Experiments:}

1. Write a story whose form is a menu and whose main character is a chef who is making the dishes listed on that menu. What about a story that takes the form of a sex manual, and whose main characters are trying out various positions, or a visionary hero whose written prophecies become part of the narrative, and which she finds herself enacting?

2. Using a maze-maker as the central character, design a narrative shape that is in itself a maze. How do these two aspects of your fiction converge, and reflect on each other? Besides texts of imagined lives of accountants, baseball scorers, and weigh-scale operators, what other score-keeping, number-crunching professions might lend themselves to a story-telling in which theme and character fuse?

3. Create a text whose form becomes an extension of characterization, such as a heroine who is a mural painter in a story that has a fan-fold shape.

4. Make the rhythm and design of a narrative analogous to the Fibonacci numbers (made by adding consecutive numbers, $0,1,1,2,3,5,8,13$, $21 \ldots$ ), and choose a mathematician as either the protagonist or the antagonist.

5. What other texts could be created that merge character, theme, and the formal properties of a book?

6. Imagine a critic in the process of trying to write a critical article defining mise-en-abyme.

\section{Double Voicedness}

[A] mode... exemplified in the peculiar play of 'voices' at work in the use of 'free indirect discourse' in Zola Neale Hurston's Their Eyes Were Watching God. Above all else, Hurston's narrative strategy seems to concern itself with the possibilities of representation of the speaking black voice in writing.... Free indirect discourse is represented in this canonical text as if it were a dynamic character, which shifts in its level of diction drawn upon to reflect a certain development of self-consciousness in a hybrid character, a character who is neither the novel's protagonist nor the text's disembodied narrator, but a blend of 
both, an emergent and merging moment of consciousness. The direct discourse of the novel's black speech community and the initial standard English of the narrator come together to form a third term, a truly double-voiced narrative mode. (Gates xxv)

Indirect discourse can be either tagged ("She said that she was hungry") or free ("She was hungry"). In both cases there are two perspectives: the narrator's and the character's. Typically, the narrator of fiction uses "standard" English, while the character's voice ("She could eat a horse") often emerges through informal diction, familiar tropes, and spoken rhythms. The double voicedness inherent in the indirect style can either emphasize the narrator's presence by effacing the linguistic details of a character's expression, or foreground a character's voice (usually through the free indirect form) so that the narrator becomes covert. In between there are interesting mixtures and ambiguities. The weighting towards the narrator or the character largely determines narrative distance, which, in turn, creates effects of coolness or empathy.

On a larger scale, the doubling of voices can emerge via a character's difference in language, culture, or class from the standardized discourse of the narrator. Out of this clash (e.g. when a character speaks in a dialect) there can be a tone of condescension, or (in Hurston's novel) the creation of an invigorating hybrid, fusing in the reader's consciousness two distinct kinds of expression.

\section{Experiments:}

1. Using standardized English, narrate briefly in the tagged indirect style the break-up of a couple. Establish a cool distance to the material.

2. Focus on one of the characters in this break-up, and, using the free indirect style with words specific to this character's voice, relate the event so that empathy results.

3. With a character vantage point other than "correct" English, and without creating a sense of condescension, use the free indirect style to narrate an experience of otherness (regional, ethnic, linguistic, etc.). Does this material feel vivid, false, innovative? Is anything except cultural self-representation a kind of appropriation of voice? If yes, is there a reduction of fiction to autobiography?

4. What effect is achieved if, as your story progresses, the separate voices of the narrator (in standard English) and the speech of the central character (in some linguistic variant) begin to merge in the telling?

\section{Dialogism}

The relationship to another's word was... complex and ambiguous in the Middle Ages. The role of the other's word was enormous at that time: there were quotations that were openly and reverently emphasized as such, or that were half-hidden, completely hidden, half-conscious, unconscious, correct, intentionally distorted, unintentionally distorted, deliberately reinterpreted and so forth. The boundary lines between someone else's speech and one's own speech were flexible, ambiguous, often deliberately distorted and confused. Certain types of texts were constructed like mosaics out of the texts of others. (Bakhtin 1981: 69)

In Bakhtin's theory of language, for any word spoken there is a complex, nuanced, agitated, oppositional history of utterances that is beyond full retrieval or elucidation, but which dialogically shapes meaning. Speech, therefore, is a kind of quoting, with every voicing of a phrase involving a sideways glance at previous 
usages, along with an awareness that nothing can be finalized even for the speaker (since there are always second thoughts and interior formulations to anticipated replies). Bakhtin therefore asserts that "no one sentence, even if it has only one word, can ever be repeated: it is always a new utterance (even if it is a quotation)" (Bakhtin 1986: 108).

A text like Eliot's The Waste Land which is full of quotations - a verbal mosaic - is startlingly new despite its assemblage of the past through echoes and allusions. Such a patchwork poem made up of the works of others is called a cento. Given the dialogic nature of language, the paradox of intertextuality is that repetition can involve semantic renewal and difference.

\section{Experiments:}

1. Have a character repeat a quotation three times such that the reader response to the first usage is one of belief in the character's sincerity, to the second one, a sense of the character's verbal irony, and on the third occasion, a sense of ambivalence due to uncertainty about the character's intention (mockery or piety?) - an ambiguity perhaps derived from the character's interior conflict.

2. Have a character quote him/herself three times (in different paragraphs) such that reader response to the first one conveys the character's smugness, to the second one, the character's sardonic self-belittling, and to the third, a sense of the character's wavering resolve.

3. Write half a page of dialogue in which one character jokingly makes a quotation from a song, book, or film, and have another character take that jesting reference seriously, with comic results. Write a half page in which one character responds to another's "pious" quote as an occasion for laughter, and trace out some serious consequences.

4. Through "dialogized" repetition, first use a word respectfully, then on its next usage transform it into one of scorn or accusation (see Shakespeare's use of the word "honourable" in Julius Caesar, Act III, first by Brutus, then by Mark Anthony). Reverse the process, and show how a character's "dialogized" insistence on self-respect changes a term of contempt into one that is affirmative (e.g. Shylock's repetition of the word "Jew" to assert his shared humanity).

5. Write a short short story in which a key word is used five times, shifting its emotional values with each recurrence.

6. In a brief phone conversation, open with a character saying something quite striking; conclude with another character deliberately distorting those initial words as a kind of rebuttal.

7. Can a story be told by creating a mosaic of three other stories?

\section{Double Focalization}

...[W]e [as readers] have access... to the last thoughts of Bergotte on his deathbed, which... cannot in point of fact have been reported to Marcel since no one - for a very good reason - could have knowledge of them. ...[I]t is irreducible by any hypothesis to the narrator's information, and... must indeed [be attributed] to the 'omniscient' novelist - ...enough to prove Proust capable of transgressing the limits of his own narrative 'system.'

...Proust manifestly forgets or neglects the fiction of the autobiographical narrator [Marcel] and the focalization which that implies.... But the truth quite obviously is that two concurrent 
codes are functioning here on two planes of reality which oppose each other without colliding. (Genette 207-08)

According to Genette, this double focalization in Proust's Remembrance of Things Past ("scandalous... for the purists of 'point of view' [Genette 208]) defies "the conditions of realistic illusion: it... transgresses a 'law of spirit' requiring that one cannot be inside and outside at the same time" (Genette 210). Although it is often a strain for a writer using a single interior narrator, "I", to encompass all aspects of a story (or even convey a simple physical self-description of the main character, hence, the omnipresence of reflecting store / bus / train windows, polished hubcaps, 'chance' photographs), ever since Henry James's use of a restricted character perspective (as a "sentient centre") such technical constraints of narration have been identified with the modern art of fiction. Therefore, to use two kinds of points of view in the same story would ordinarily seem clumsy or incoherent, but Genette argues that the double focalization of Proust's novel results in "textual coherence and narrative tonality" (Genette 208) and, in fact, "no code prevails anymore and... the very notion of infraction becomes outworn" (Genette 210). Such a postmodernist disregard for narrative conventions partly relates to Brecht's alienation effect, where the audience is constantly reminded of art as artifice, and denied the uncomplicated emotions of realistic illusion.

\section{Experiments:}

1. Take a story you have written consistently from the first-person limitedinterior point of view, and rewrite part of it using the omniscient point of view, seeking to preserve narrative clarity. Is it possible? Has the greater story-telling freedom been achieved at the cost of characterization or psychological intensity? Has the tone altered to something more playful?

2. Take one of your stories that is consistent in its point of view throughout, and in a postmodernist manner transgress the chosen narrative code by inserting various types of focalization, so that the reader is constantly "alienated", unable to comfortably settle into a sustained realistic illusion because the revised text always draws attention to itself by its shifting perspectives. How is such a rewritten text disturbing, interesting, assaultive, provocative? How does it alter the reader's role and expectations?

3. "[Frank] Gehry's California Aerospace Museum, ...in southeastern Los Angeles, introduced the 'village of forms' concept, which he would develop further in many subsequent projects. Instead of aiming for architectural unity to which all elements contributed, Gehry's notion was to break the structure down into discrete, dissimilar forms that did not necessarily come together at all; this struck him as a truer expression of contemporary life" (Tomkins 42). If the prevailing aesthetic has been one that Coleridge terms "organic unity", what chaos or excitement occurs when a story is put together with dissimilar forms, with shapes "that do not necessarily come together at all"?

\section{Scripts}

...[D] evelopments in language theory and cognitive science that have occurred after the heyday of structuralist narrative poetics... may throw light on the problem of what defines narrative. Of special relevance is research in the field of artificial intelligence on knowledge structures that have been characterized as schemata, scripts, and frames. For Dennis Mercadal a script is a 'description of how a sequence of events is expected to unfold.... A script is similar to a frame in that it [a script] represents a set of 
expectations.... Frames differ from scripts in that frames are used to represent a point in time. Scripts represent a sequence of events that take place in a time sequence.' ... This research suggests that the mind draws on a large but not infinite number of 'experiential repertoires,' of both static (schematic or framelike) and dynamic (scriptlike) types. Stored in the memory, previous experiences form structured repertoires of expectations about current and emergent experiences. Static repertoires allow me to distinguish a chair from a table or a cat from a bread box; dynamic repertoires help me to know how events typically unfold during common occasions like birthday parties and to avoid mistaking birthday parties for barroom brawls or visits to the barber. (Herman 1047)

If cognitive research suggests that memory often stores knowledge as scripts, then much of human understanding can be described as "'a process by which people match what they see and hear to pre-stored groupings of actions that they have already experienced"' (Schank and Abelson quoted in Herman 1048). This kind of matching would reduce, or maybe even avoid, the imaginative demands (and duration) inherent in repeatedly engaging the complexity of the world through fresh perceptions and new inferences. Having learned hundreds or thousands of these scripts, each with its own Aristotelian beginning, middle, and end, and ordered by chronology and causation, humans possess a narrative representation of many aspects of their cultural world, so that, in effect, future experiences have already been largely anticipated and sorted out by past ones that the brain has stored as stereotypical process analyses involving consecutive steps leading from an expected beginning to a preconceived end. Literary narratives require familiarity with many of these scripts as part of an understanding of what is happening in a novel, and scripts perhaps act as the prototypes for such storytelling. Furthermore, some scripts, such as "reading a novel" model our dependency on prior experience, and our stored scripts of previous textual experiences as readers of fiction create expectations that may habituate us in advance to a "new" novel.

Literature, though it depends on the reader's knowledge of many familiar situations and stereotypical events, mostly uses the scripts of the world as backdrop (except in satire). Since literary value is allied to the mystique of the original, "[t]he formal impetus, the constitutive gesture, of literary fiction has been the rejection or at least the backgrounding of scripts in which prior texts were anchored and the complementary foregrounding of new scripts matched to changing ideas about narrative" (Herman 1054). So, while scripts may offer the novel its prototypical form, a shorthand means of representing the world, and its very followability, paradoxically, literature might be defined as (in a Hollywood nightmare) eternal script revision.

\section{Experiments:}

1. If the process of cutting the lawn or baking a cake is already a script we have stored in our heads, what has to be added to make a literary narrative? Is naming a character and giving a time frame enough? e.g. "At 12:37 on Friday, Oct. 31, Jim Churcher pulled the cord that started his lawn mower." Try adding description (say, of the pattern of mowing). Does this specificity somehow create emotion or tension or character? Invent an incident (such as tangling an electrical cord while turning a corner, or running into a rock, or over dog-shit). How do these micro-actions create interest and lift the lawn-mowing script out of mere how-to-manual prose?

2. Create two parallel narratives that grow out of a specific everyday situation which has become stylized as a cultural script, such as brushing your teeth, or ordering food at a restaurant, or boarding a plane, or getting money from 
a bank machine. Although the same sequence of steps occur in each narrative sketch, have you managed to create a drama out of descriptive or narrative dissimilarities in the varying performances of this single script? Make the dramatic counterpointing greater by having the two characters contrast in age, gender, or ethnicity, or class.

3. According to Herman, "[t]he processing of narratives is more complex when they inhibit what might be termed the naïve application of scripts and promote instead reflection on the limits of applicability of the scripts being invoked" (Herman 1055). Using the same script, write three brief narratives that grow increasingly complex, that is, become harder and harder to paraphrase as a stereotypical event sequence. How is literary interest related to complexity?

4. Sketch out a story that might arise from three different scripts which overlap in time, such as the dating script, the watching the movie script, and the introduction to a stranger script. Is readerly interest partly correlated with the number of scripts used in fiction? How many scripts are there in a bestselling novel besides sex and shooting and shopping and travel? Do genres have typical scripts, such as rescue for the adventure novel, or going to school for the Bildungsroman, or seduction for the romance?

5. "...I know what to do when the waiter comes up to me in a restaurant because I have been in restaurants before and remember the standard roles of waiter and customer" (Herman 1050). Write a story that arises from the breakdown of such a script, one involving dialogue between two characters. Is this likely to be comic or playful, creating laughter out of the unexpected, or is it as likely to be serious and pathetic, and lead to a disclosure of genuine feeling, perhaps due to some inability to sustain appropriate social roles (too drunk, crazy, distressed, enraged). Explore a character who can't follow an expected script.

6. A naïve narrator might be understood as a child just learning worldly knowledge, one for whom the scripts of sequential behaviour have not yet become cultural givens. Through the eyes of a five-year-old, show in a brief narrative the process of learning about one stereotypical process. Sci-fi might be the maximal use of such a naïve narrator, i.e. a point of view with no applicable scripts memorized for, say, Saturn. Write down in a diary form the sensory experience and intellectual extrapolations and psychological stress of a Martian who has come to earth scriptless, without a worldly grasp of our usual configurations and predictable sequences. (See Claude Raines's poem, "A Martian Sends a Postcard Home".)

7. Depict the loneliness of an old person as one who is finding that familiar scripts no longer apply to the world outside, and the character is bewildered by new phenomena for which she or he has no script.

8. Does the moment of recognition or epiphany in a story occur when some cherished script of the hero no longer fits his experience? If worldly understanding is stored in memory as scripts, and constitutes the basis for a character's behaviour, what happens to these everyday scripts when the world is drastically transformed (say, through the invention of the birth control pill or the dropping of the first bomb from a plane on people)? How do such macro-scripts as urbanization or Marxism (and its relative disappearance) affect the repertoire of smaller scripts by which individuals and characters in novels - enact their future lives?

9. The scripts of human memory can be viewed as akin to mimesis, a mode of representing action in the world. A mise-en-abyme effect thereby results for all literature, since characters in fiction (and in drama and film more overtly) mimic the way every human performs a variety of mimic procedures. The pan-human mirroring of the world as scripts held in memory anticipates and parallels novelistic mimesis, which, in turn, selects and combines and updates and queries worldly scripts. Does the shaping of 
fictional narratives then become a way to consolidate, and even to create, knowledge?

When I have asked emerging writers to try out some of these experiments in creative writing workshops at colleges and universities in Canada, most students have been happy to focus their imaginative energies briefly in the theoretical ways specified, and many have then been quite willing to read aloud their newly achieved work. A few have balked. Interestingly, though, such students have not always resisted subsequent and different experiments in narrative form.

Perhaps the exercise that writers have carried out most vividly is one in defamiliarization, where they describe in concrete language how a kitchen appears after the death of someone intimate without ever mentioning that death. For students, the most engaging exercise in closure among those listed above has been the one in which they write the final paragraph of a published short story and then compare their version to the author's; often they delight in discovering proximity, though sometimes the student writers have composed endings that suggest alternative narrative possibilities. (What also is instructive in this exercise is the need to imitate the original's voice and tone in order to make the newly created ending join seamlessly with the preceding story.) The experiments with mise-enabyme I have used sparingly in workshops, but those student writers attracted to postmodernism rather than realism have creatively shaped stories out of a sense of connection between planes of telling. Double voicedness is a concept I have introduced into many classes, where the exercises in narrating a break-up of an imagined couple through the use of different diction and speech patterns have usefully clarified such terms as irony and empathy, as well as opening out for discussion the notion that English has many "Englishes", fused or separate. Some of the experiments listed under Bakhtin's term "dialogism", such as those involving "dialogized" repetition, have also proved illuminating in creating an awareness of how to achieve ironic or sincere effects, and these experiments make clear as well that words are not inert, but shifting, contested, and dramatic, thereby enlarging writerly understanding of language and expressiveness. Only in advanced workshops with sophisticated writers have I introduced Genette's term, double focalization. Mere incoherence can result from contradictory ways of telling, but, as a creative writing teacher, I believe that it can be salutary on occasions to explode a convention such as unity of point of view if only to understand its strategic value. In some cases, such conscious departures from the norm can free up other expressive possibilities that can make for a narration that is unexpectedly potent. Perhaps the main usefulness of "scripts" in student writing is to counter the tendency in much of beginning writing for characters to exist only as bodiless consciousness; by narrating a process such as cutting the lawn or baking a cake, the student writer has to remember that the character is participant in the outside world and subject to duration, preconditions for more significant actions and plot development.

Overall, I feel these narrative concepts and creative experiments can be helpful. For several student writers these exercises have acted as originating fragments in the creation of fuller stories. Less directly, such experiments can at once focus and broaden story-telling horizons. Also importantly, these theoretical exercises can offer new fiction writers confidence that they can understand and revise their initial narrative choices.

\section{References}


Bakhtin, Mikhail. The Dialogic Imagination: Four Essays. Ed. Michael Holquist. Trans. Caryl Emerson and Holquist. Austin: U of Texas P, 1981. Return to article

Bakhtin, Mikhail. Speech Genres and Other Late Essays. Eds. Caryl Emerson and Michael Holquist. Trans. Vern W. McGee. Austin: U of Texas P, 1986. Return to article

Baldick, Chris. The Concise Oxford Dictionary of Literary Terms. Oxford: Oxford UP, 1990. Return to article

Barthes, Roland. Image - Music - Text. Trans. Stephen Heath. New York: Hill and Wang, 1977. Return to article

Bowering, George. "Writer Writing, Ongoing Verb". George Bowering and Robert Kroetsch in conversation. Ed. Betty A. Schellenberg. In Future Indicative: Literary Theory and Canadian Literature. Ed. John Moss. Ottawa: U of Ottawa P, 1986. 5-24. Return to article

Gardner, John. The Art of Fiction: Notes on Craft for Young Writers. New York: Vintage, 1985. Return to article

Gates Jr., Henry Louis. The Signifying Monkey: A Theory of African-American Literary Criticism. New York: Oxford UP, 1988. Return to article

Genette, Gérard. Narrative Discourse: An Essay in Method. Trans. Jane E. Lewin. Ithaca, N.Y.: Cornell UP, 1980. Return to article

Herman, David. "Elements of a Postclassical Narratology". PMLA 112 (1997): 1046-1059. Return to article

Kermode, Frank. The Sense of an Ending: Studies in the Theory of Fiction. London: Oxford UP, 1968. Return to article

Kroetsch, Robert. "Writer Writing, Ongoing Verb." George Bowering and Robert Kroetsch in conversation. Ed. Betty A. Schellenberg. In Future Indicative: Literary Theory and Canadian Literature. Ed. John Moss. Ottawa: U of Ottawa P, 1986. 5-24. Return to article

Lodge, David. The Art of Fiction: Illustrated from Classic and Modern Texts. London: Penguin, 1992. Return to article

Rimmon-Kenan, Shlomith. Narrative Fiction: Contemporary Poetics. London: Routledge, 1983. Return to article

Shklovsky, Victor. "Art as Technique". Russian Formalist Criticism: Four Essays. Trans. Lee T. Lemon and Marion J. Reis. Lincoln: U of Nebraska P, 1965. 3- 24. Return to article

Tomkins, Calvin. "The Maverick". The New Yorker 7 July 1997: 38-45. Return to article

Note: An earlier version of this paper appeared in Journal of English and Foreign Languages (India)

Keith Harrison, born in Vancouver, studied at UBC, California (Berkeley), and McGill (PhD, Dean's Honours List). He has published many scholarly articles, focused on such writers as Byron, Patrick Lane, Malcolm Lowry, Pat Lowther, Gabriel García Márquez, Herman Melville, Ian McEwan, Michael Ondaatje, and Shakespeare. He has also written essays on documentary film, comics, exploration literature, narrative theory, and hockey. As a writer of fiction, Harrison has completed three novels, Dead Ends (1981), a finalist for the Best First Novel in Canada Award, After Six Days (1985), and Eyemouth (1990), shortlisted for a QSPELL Award. His collection of short stories, Crossing the Gulf (1998) includes a piece that won the Okanagan Short Story Award. A non-fiction novel, Furry 
Creek (1999), was selected for the BC 2000 Award and nominated for the Ethel Wilson Fiction Prize. He has edited an anthology, Islands West: Stories from the Coast, that appeared in the fall of 2001. He teaches in the Departments of English and Creative Writing at Malaspina University-College, and lives on Hornby Island, $B C$.

\section{TEXT}

Vol 7 No 1 April 2003

http://www.griffith.edu.au/school/art/text/

Editors: Nigel Krauth \& Tess Brady

Text@griffith.edu.au 